P.Scalfaro

J.J.Chesaux

P. A. Buchwalder

J. Biollaz

J. L. Micheli
Received: 26 June 1997

Accepted: 1 December 1997

P. Scalfaro - J.L. Micheli

Division of Neonatology,

University Hospital, CH-1011 Lausanne,

Switzerland

\section{J.J. Chesaux}

Department of Paediatrics,

University Hospital, CH-1011 Lausanne,

Switzerland

P. A. Buchwalder · J. Biollaz

Division of Clinical Pharmacology,

University Hospital, CH-1011 Lausanne,

Switzerland

P. Scalfaro ( )

Telethon Institute for

Child Health Research,

Princess Margaret Hospital for Children, P.O.Box 855, West Perth WA 6872 ,

Australia

Fax: +61 (8) 93883414

email: pietros@ichr.uwa.edu.au

\section{Severe transient neonatal lactic acidosis during prophylactic zidovudine treatment}

\begin{abstract}
Zidovudine (ZDV) treatment during pregnancy, delivery and the postnatal period is effective in reducing the maternal-infant transmission of the human immunodeficiency virus. Reported adverse effects in the neonate during this longterm treatment are bone marrow suppression and elevation in aspartate aminotransferase activity. We report a case of severe $\mathrm{ZDV}$-associated lactic acidosis in a neonate, which resolved rapidly following discontinuation of ZDV. The mechanisms leading to this side effect are poorly understood.
\end{abstract}

Key words HIV infection. Zidovudine $\cdot$ Neonate $\cdot$ Prophylaxis . Lactic acidosis

\section{Introduction}

The prophylactic zidovudine (ZDV) treatment of HIVpositive mothers during pregnancy and delivery and of her neonate during the first 6 weeks of life has been shown to decrease the transmission rate of HIV from 26 to $8 \%$ in a recent randomised, double-blind, placebo-controlled trial [1]. The risk-benefit ratio of the recommended regimen clearly favours prophylaxis. There are theoretical and rare but severe risks, which, however, have to be known when starting prophylactic ZDV treatment for a mother and her neonate.

\section{Case report}

A 16-year-old African primigravida, was diagnosed HIV-positive at 24 weeks of gestation (CDC AIDS classification: A2) and received prophylactic ZDV treatment according to Swiss national guidelines [2]. Following an uneventful pregnancy, a $2.5-\mathrm{kg}$ gir] was delivered electively at 35 weeks of gestation by caesarean section under intravenous (i.v.) ZDV administration. Umbilical $\mathrm{pH}$ was 7.27. Apgar score was 6/5/8. There was progressive onset of severe respiratory distress due to persistent fetal circulation (PFC) diagnosed on the basis of refractory hypoxemia (fractional inspired oxygen 1.0, arterial oxygen tension $39 \mathrm{~mm} \mathrm{Hg}$, arterial-alveolar $\mathrm{O}_{2}$ tension ratio 0.06 ) with normal chest $\mathrm{X}$-ray, absence of congenital heart disease and s suprasystemic pulmonary pressure on echo Doppler. Treatment included intubation and mechanical ventilation with morphine sedation, correction of anaemia (haemoglobin 
Table 1 Clinical and laboratory values before, during and after the occurrence of severe lactic acidosis in a zidovudine-treated neonate $\left(\mathrm{FIO}_{2}\right.$ fractional inspired oxygen, $\mathrm{PaCO}_{2}, \mathrm{PaO}_{2}$ arterial car- bon dioxide and oxygen tensions, $B E$ base excess, $A S A T$ aspartate aminotransferase, $A L A T$ alanine aminotransferase, $V$ ventilated, $N$ normal, $N A$ not available)

\begin{tabular}{|c|c|c|c|c|c|c|c|c|}
\hline & \multicolumn{8}{|c|}{ Age in days } \\
\hline & 6 & 7 & 8 & 9 & 10 & 11 & 12 & 16 \\
\hline $\mathrm{FIO}_{2}(\%)$ & 0.30 & 0.25 & 0.29 & 0.21 & 0.30 & 0.28 & 0.21 & 0.21 \\
\hline Respiratory rate $\left(\min ^{-1}\right)$ & $\mathrm{V}$ & 65 & 60 & 90 & $\mathrm{~V}$ & 70 & 60 & 50 \\
\hline Heart rate $\left(\mathrm{min}^{-1}\right)$ & 136 & 140 & 152 & 160 & 140 & 158 & 146 & 140 \\
\hline Mean arterial pressure $(\mathrm{mm} \mathrm{Hg})$ & 44 & 42 & 58 & 68 & 64 & 64 & 60 & 50 \\
\hline Urine output (ml/kg per h) & 5.0 & 3.2 & 4.7 & 3.4 & 2.6 & 5.3 & 2.8 & $N$ \\
\hline Body weight $(\mathrm{g})$ & NA & 2860 & 2880 & 2740 & NA & 2610 & 2580 & 2540 \\
\hline Enteral formula $(\mathrm{ml} / 24 \mathrm{~h})$ & 40 & 70 & 120 & 160 & 0 & 0 & 160 & 420 \\
\hline i. v. dextrose-amino acid solution $(\mathrm{ml} / 24 \mathrm{~h})$ & 220 & 210 & 190 & 90 & 240 & 300 & 150 & 0 \\
\hline Total fluids (ml/kg per $24 \mathrm{~h}$ ) & 104 & 110 & 124 & 100 & 100 & 120 & 124 & 168 \\
\hline $\mathrm{pH}$ & 7.42 & 7.36 & 7.35 & 7.14 & 7.36 & 7.38 & 7.38 & 7.36 \\
\hline $\mathrm{Pa}^{\mathrm{a}} \mathrm{CO}_{2}(\mathrm{mmHg})$ & 38.6 & 43.3 & 47.4 & 25.3 & 34.0 & 42.0 & NA & $\mathrm{NA}$ \\
\hline $\mathrm{P}^{\mathrm{a}} \mathrm{O}_{2}(\mathrm{mmHg})$ & 95.4 & 109.5 & 85.2 & 79.5 & 91 & 90 & $\mathrm{NA}$ & $\mathrm{NA}$ \\
\hline $\mathrm{BE}(\mathrm{mmol} / \mathrm{l})$ & 0.7 & -1.0 & 0.9 & -18.9 & -8.5 & -0.1 & -1.9 & -2.4 \\
\hline lactic acid (mmol/l) & 1.9 & $\mathrm{NA}$ & NA & 14.0 & 2.6 & 2.0 & $\mathrm{NA}$ & $\mathrm{NA}$ \\
\hline $\mathrm{Na}(\mathrm{mmol} / \mathrm{l})$ & 137 & 137 & 144 & 142 & 143 & 144 & 141 & 143 \\
\hline $\mathrm{K}(\mathrm{mmol} / \mathrm{l})$ & 5.6 & 5.6 & 5.1 & 5.7 & 4.0 & 2.9 & 6.2 & 5.9 \\
\hline Urea $(\mathrm{mmol} / \mathrm{l})$ & 3.4 & 2.9 & NA & 7.2 & 7.2 & 2.8 & NA & NA \\
\hline Creatinine $(\mathrm{mmol} / \mathrm{l})$ & 65 & 69 & $\mathrm{NA}$ & 64 & NA & 50 & NA & NA \\
\hline ASAT (IU/l) & 31 & NA & NA & 40 & 96 & 40 & NA & NA \\
\hline ALAT (IU/1) & 5 & NA & NA & 9 & 13 & 22 & $\mathrm{NA}$ & $\mathrm{NA}$ \\
\hline
\end{tabular}

${ }^{a}$ All day 9 values were collected $2 \mathrm{~h}$ prior to reintubation

$103 \mathrm{~g} / \mathrm{l}$, mean corpuscular volume $117 \mathrm{fl}$ ), inotropic support, alkalinization by hyperventilation and bicarbonate administration, and continuous intravenous magnesium therapy [3]. Ampicillin was given from days 1 to 10 . Continued ZDV prophylaxis against HIV transmission was administered orally at a dose of $2 \mathrm{mg} / \mathrm{kg}$ every $6 \mathrm{~h}$ the first day, then with the same dosage i.v. from days 2 to 7 and orally from days 8 to 9 .

PFC resolved over $48 \mathrm{~h}$ and the patient was successfully extubated on day 7 after moderate fluid restriction and three doses of frusemide $(0.8 \mathrm{mg} / \mathrm{kg})$ on days 5 and 6 . Fluids were given according to our unit's policy with a dextrose-amino acid solution during the first 13 days. The total amount of $i . v$. amino acids was always less than $3.0 \mathrm{~g} / \mathrm{kg}$ per day. Enteral feeds with formula were started on day 2 (i. v. to enteral fluid ratio given in Table 1 ).

The patient was doing well, breathing spontaneously in air, partially enterally fed on day 9 , when she developed a sudden onset of respiratory distress without haemodynamic instability (Table 1). On physical examination, a mild hepatomegaly and five petechial lesions on the abdomen were noted. There was no abdominal distension or tenderness. Laboratory analysis showed an unexpected increase in serum lactate at $14 \mathrm{mmol} / \mathrm{l}$ with severe metabolic acidosis partially compensated for by hyperventilation (Table 1) confirmed on repeat analysis. The patient was reintubated due to clinical worsening of the respiratory distress. Acute management included the administration of $2 \mathrm{mEq} / \mathrm{kg}$ of bicarbonate and $10 \mathrm{ml} /$ $\mathrm{kg}$ of albumin and discontinuation of both the enteral feeds and ZDV treatment. After $18 \mathrm{~h}$ the infant was successfully extubated.

Investigations showed a twofold increase in aspartate aminotransferase (ASAT) and a slight increase in urea. Blood glucose, blood cell count, coagulation, renal function, serum creatinine kinase, bilirubin, chest and abdominal X-ray and blood, urine and stool cultures were all normal. Lactate and ASAT values returned to normal within 6 and $14 \mathrm{~h}$, respectively. The metabolic acidosis disappeared over $24 \mathrm{~h}$ without repeated bicarbonate administra- tion. More common causes for lactic acidosis such as hypoxia, shock or hypotension were excluded on a clinical basis (cf. also Table 1).

The patient was discharged on day 28. ZDV treatment has not been reinstated and no alternative antiviral prophylactic treatment introduced. At 11-month follow-up, the patient showed no clinical or serological signs of HIV infection, no metabolic acidosis and normal growth and development.

\section{Discussion}

Zidovudine, a nucleoside analogue phosphorylated by thymidine kinase in healthy and HIV-infected cells, is a potent inhibitor of HIV reverse transcriptase and has also a weak affinity for the mammal DNA polymerase$\gamma$. Usual adverse effects in the neonate are a mild macrocytic anaemia and a slight increase in ASAT [4]. Anaemia is considered to be due to the sensitivity of erythrocyte precursor cells to ZDV. The increase in ASAT may be of hepatic or muscular origin and usually has a benign course. Both side effects were observed in this patient with no major consequences.

Severe lactic acidosis in ZDV-treated adults was recently described. Chattha et al. [5] reported seven AIDS patients (aged $43 \pm 8$ years) with cardiovascular collapse and severe lactic acidosis $(14.3 \pm 2.6 \mathrm{mmol} / \mathrm{l})$, despite having normal cardiac function and oxygen delivery. Four of these patients were receiving long-term ZDV therapy. It was concluded that ZDV-associated lactic acidosis was a major comorbid event leading to 
death. Since then, other similar adult cases have been reported [6].

In this patient, the development of lactic acidosis on day 9 resolved rapidly following discontinuation of $\mathrm{ZDV}$. This suggests that ZDV therapy alone or in conjunction with other factors may be responsible for this side effect. There was no clear evidence implicating a more common cause for lactic acidosis, like circulatory insufficiency, infection or metabolic imbalance. The patient was in good clinical condition when the acidosis suddenly developed over a few hours. Although mild hypovolaemia may have contributed, it is unlikely to be a major causative factor underlying the severe acidotic episode. The only clinical signs (mild liver enlargement and a few petechiae) were not consistent with any particular aetiology. In the absence of a more likely cause a pharmacological explanation has to be considered.

Plasma levels of ZDV were not determined in this case, therefore a pharmacokinetic explanation for the observed toxic event can be hypothesised but not proved. The dose of ZDV given to this 35-week-old infant was that recommended for neonates [2]. One could argue that administering the same dose i.v. as the orally recommended one may have played a role. However, since a decreased first-pass metabolism and a greater bioavailability of ZDV ( 89 vs $60-70 \%$ ) have been shown in neonates after oral administration compared to infants [7], the increase in the drug exposure following i.v. administration is minimal and unlikely to play a crucial role in the adverse event.

Total body clearance of ZDV is influenced by gestational age and liver metabolic maturity because ZDV is mainly eliminated by hepatic metabolism to a glucuronide compound. The rest undergoes tubular renal excretion. The serum half-life is $3 \mathrm{~h}$ in neonates compared to nearly $2 \mathrm{~h}$ in older infants [7]. Competition for ZDV glucuronidation with endogenous substrates (bilirubin) or durgs (morphine) is a possible interaction leading to increased plasma levels. Furthermore, it has been shown that renal ZDV excretion can be inhibited by drugs transported by either the tubular organic anion or cation transport system [8]. Drug interaction at this level (with morphine and frusemide in this case), in addition to immature renal function, is therefore a possibility. This patient did receive these drugs, but only during the first 6 days and at minimal dosage, which makes their potential interaction negligible.

The adult cases usually show a latency of several months between the initiation of ZDV treatment and the occurrence of lactic acidosis. This patient was exposed to ZDV during nearly 3 months, as this drug easily crosses the placenta. To our knowledge, there is no explanation why there is such a long delay between the start of ZDV treatment and the development of lactic acidosis. A subclinical direct cytotoxic effect may be hypothesised: the affinity of ZDV for mitochondrial DNA polymerase- $\gamma$ reduces mitochondrial DNA synthesis, which may contribute to a delayed cytotoxicity as shown in vitro [9]. This may lead to increased lactate production by reducing the oxidation of the reduced form of nicotinamide-adenine dinucleotide (NAD) to NAD+ [10].

It is questionable whether the initial persistent fetal circulation or another unrecognised condition may have played a role in the pathogenesis of the lactic acidosis in this patient, possibly by unmasking a subclinical biological toxicity. The occurrence several days after the recovery of the circulatory problems, the fact that lactate values were normal before the collapse, and the good clinical condition of the patient when the lactate increased to not support this hypothesis.

The recommended length of neonatal prophylactic $\mathrm{ZDV}$ therapy is 6 weeks, a decision based on the risk of finding maternal infected cells in the neonate's circulation during the first few weeks of life. This case could contribute in the decision making concerning the optimal length of neonatal ZDV therapy when considering the risk-benefit ratio.

In conclusion, severe lactic acidosis is a life-threatening, though rare, side effect of neonatal ZDV therapy of which the paediatric and neonatal intensivist must be aware. The optimal length of postnatal therapy has still to be established and should consider this possible complication. We cannot conclude whether the severe lactic acidosis seen in this patient was dose-dependent.

\section{References}

1. Connor EM, Sperling RS, Gelber R, Kiselev P, Scott G, O'Sullivan MJ, VanDyke R, Bey M, Shearer W, Jacobson RL et al (1994) Reduction of maternalinfant transmission of human immunodeficiency virus type 1 with zidovudine treatment. $\mathrm{N}$ Engl J Med 331: $1173-1180$
2. Pädiatrische AIDS-Gruppe Schweiz (PAGS), Kommission der Schweizerischen Gesellschaft für Pädiatrie, Subkommission Klinik (SKK) der Eidgenössischen Kommission für AIDS-Fragen (EKAF). Arbeitsgruppe HIV der Schweizerischen Gesellschaft für Gynäkologie und Geburtshilfe (1994) Zidovudine zur Prophylaxe der HIV Übertragung von der infizierten Mutter auf ihr Kind. Schweiz Ärztezeitung 75: 1508-1509
3. Tolsa JF, Cotting J, Sekarski N, Payot M, Micheli JL, Calame A (1995) Magnesium sulphate as an alternative and safe treatment for severe persistent pulmonary hypertension of the newborn. Arch Dis Child Fetal Neonatal Ed 72: F184-187 
4. Monpoux F, Dageville C, Bongain A, Sirvent N, Maillotte AM, Mariani R, Gillet JY (1997) Tolérance biologique de l'azidothymidine administrée en période périnatale chez le nouveau-né de mère VIH-1 séropositive. Ann Pediatr 44: 87-93

5. Chattha $\mathrm{G}$, Arieff AI, Cummings $\mathrm{C}$, Tierney LM Jr (1993) Lactic acidosis complicating the acquired immunodeficiency syndrome. Ann Intern Med 118: 37-39
6. Masio C, Jacomet C, Jupas JJ, Lebrette MG, Rozenbaum W (1994) Acidose lactique chez des patients infectés par le VIH. La Presse Médicale 23: 717

7. Boucher FD, Modlin JF, Weller S, Ruff A, Mirochnick M, Pelton S, Wilfert C, McKinney R Jr, Crain MJ, Elkins MM et al (1993) Phase I evaluation of zidovudine administered to infants exposed at birth to the human immunodeficiency virus. J Pediatr 122: 137-144

8. Chatton JY, Munafo A, Chave JP, Steinhauslin F, Roch-Ramel F, Glauser MP, Biollaz J (1992) Trimethoprim, alone or in combination with sulphamethoxazole, decreases the renal excretion of zidovudine and its glucuronide. $\mathrm{Br} \mathrm{J}$ Clin Pharmacol 34: 551-554
9. Chen $\mathrm{CH}$, Vazquez-Padua $\mathrm{M}$, Cheng YC (1991) Effect of anti-human immunodeficiency virus nucleoside analogs on mitochondrial DNA and its implication for delayed toxicity. Mol Pharmacol 39: 625-628

10. Gopinath R, Hutcheon M, CheemaDhadli S, Halperin M (1992) Chronic lactic acidosis in a patient with acquired immunodeficiency syndrome and mitochondrial myopathy: biochemical studies. J Am Soc Nephrol 3: 1212-1219 